\title{
Organization of taking exams of university students in online format: problems and opportunities
}

\author{
Egor Borisov ${ }^{1, *}$, Elena Petrenko ${ }^{2}$, Elena Zatsarinnaya ${ }^{3}$, Alexey Romanov ${ }^{4}$, Vera Cherkina ${ }^{5}$, \\ and Lyudmila Sotnikova ${ }^{6}$ \\ ${ }^{1}$ North-Eastern Federal University, 58 Belinsky str., 677000, Yakutsk, Russia \\ ${ }^{2}$ Kuban state agrarian university named after I. T. Trubilin, 350044, 13 Kalnina str., Krasnodar, \\ Russia \\ ${ }^{3}$ Plekhanov Russian University of Economics, Stremyanny lane 36, 117997, Moscow, Russia \\ ${ }^{4}$ Russian University of Transport (MIIT), 9b9 Obrazcova Str., Moscow, Russia \\ ${ }^{5}$ Moscow State University of Civil Engineering, Yaroslavskoe sh. 26, Moscow, Russia \\ ${ }^{6}$ Financial University under the Government of the Russian Federation, Leningradsky prospect 49, \\ Moscow, 125993, Russia
}

\begin{abstract}
Digitalization and automation in all sectors of the economy have increased the efficiency and effectiveness of various systems and processes. Online technologies are also widely used in the higher education system. Online learning, e-learning, e-learning tools and digital assessments are not innovations in the full sense of the word, but the widespread use of these technologies took place in mid-2020, due to the COVID-19 pandemic. The using the online format of training by universities and schools in the spring of 2020 was mostly spontaneous and forced, but later, due to the complication of the sanitary and epidemiological situation in the world, as well as in order to improve electronic pedagogical technologies in the field of certification of university students, this technology became the subject of consideration by specialists from different industries and, above all, from the field of pedagogy. The authors made attempts to study the main problems of University students passing exams and tests in an online format in order to avoid them in the future, and also developed ways to improve this technology.
\end{abstract}

\section{Introduction}

The learning and teaching process is being transformed from a regular lecture hall designed for a specific audience of passive students to a more active learning environment. In the modern period, the COVID-19 pandemic caused the transition to this form of teaching, when thousands of students had to urgently adapt to the online format of training and passing exams [1]. Many engineering innovations were introduced during the short period of time thus causing significant tensions among both the users and developers [2].

\footnotetext{
${ }^{*}$ Corresponding author: kostya15.00@mail.ru
} 
Universities are developing extensive online offerings to increase their international load and promote mass distribution of higher education. Distance learning can provide significant competitive advantages to regional universities that have more attractive quality to price ratio [3]. These protocols, based on growing policy challenges to train more graduates, challenged traditional university models of full-time student attendance at higher education institutions. The development of software for online exams has been a systematic and technological alternative to the final exam at the end of the course, designed to finally test students ' knowledge of the courses they have studied.

As a result of the COVID-19 pandemic, the initial response of higher education in many countries was to delay exams. However, as the pandemic continues, the need to switch to either an online exam or an alternative assessment has become more urgent.

The advent of online exams, electronic exams, and "bring with you" models has become an alternative to large-scale exam rooms with exams conducted using paper and pen. Each of them offers new opportunities to incorporate innovative teaching and assessment techniques where exams are considered to be necessary. In addition, some studies show that online exams can distinguish true passing from true failure with a high level of accuracy, but there is no unified view of the researchers on this issue. For this reason, it is necessary to consolidate existing practices to support the spread and further innovation in online learning and examination. Such systems can be created to provide formative feedback and evaluate learning outcomes, but the main problem of conducting final exams in online format is the authentication of learning. It allows us to guarantee that the student whose name is in the student register is the student who performs the evaluated work [4].

As many scholars point out, fraud is a common component of the modern student experience, although its exception is a goal to strive for. There are opinions that it is necessary to include in contracts with universities a section prohibiting fraud during exams. In this regard, it is particularly valuable to find methods that can support the integrity of students ' assessment, including during dynamic changes in the curriculum. A proper incentives for government regulation of this specific area of digitalization is also in place $[5]$.

\section{Materials and methods}

To achieve the goal of this article, a systematic review of the literature was conducted as part of the study. A fairly wide range of literature on online exams was analyzed. The search was carried out by the corresponding keywords, and the articles themselves were subsequently subjected to double full-text review. An inductive thematic approach was also used to identify common themes identified in each article.

\section{Results}

The information obtained as a result of studying the article was systematized in several sections.

\subsection{The attitude of students towards online learning format}

According to the results of a survey conducted in the literature $[6,7,8]$, today's students prefer online exams to paper exams $(68.75 \%)$. Among the reasons given for preference is the increased speed and ease of editing responses, with one study showing that two - thirds $(67 \%)$ of students reported a positive experience of taking online exams [9]. 
Students believe that online exams allow for more reliable assessment, with $78 \%$ of students reporting consistency between the online environment and their future real-world environment [9].

Students believe that online exams allow for more reliable assessment, with $78 \%$ of students reporting consistency between the online environment and their future real-world environment [9].

Students believe that online exams save time (75.0\% of students surveyed) and are more economical $(87.5 \%)$ than paper exams. They provide more flexibility in passing exams with faster access to remote student papers $(87.5 \%)$, and students trust the results of online exams rather than paper ones (78.1\%) [9].

The majority of students $(59.4 \%)$ believe that the online exam environment makes cheating easier. More than half $(56.25 \%)$ of students believe that the lack of skills in the field of information interaction and technology (ICT) does not negatively affect performance in online exams.

Almost a quarter $(23 \%)$ of students reported that the most preferred font (type) was Arial, which was chosen for inclusive design and readability on the Internet and print considerations.

Almost all (87\%) students preferred black text on a white background (87\%). As for onscreen time counters, the countdown counter was the most preferred option (42\%) compared to a traditional analog clock $(30 \%)$ or an ascending counter (22\%). Many systems allow students to set a preferred reminder or notification about the remaining time, including the remaining 15 minutes (35\% of students prefer), the remaining 5 minutes $(26 \%)$, the middle of the exam (15\%), or the remaining 30 minutes $(13 \%)$ [9].

\subsection{The level of student performance}

Several studies in the sample indicated that there was no difference in scores between the survey results for different methods of administration. For example, student performance did not differ significantly in final exam scores for online and traditional exams. This is confirmed by a test for the validity and reliability of computer and paper assessments, which did not demonstrate a significant difference and equality of the estimates identified in the two modalities [10].

When considering students' perceptions of research documented in our sample, online exams usually received positive ratings. In a small sample of 34 graduate students, respondents viewed online learning assessment positively (67.4\%). Students also believe that this contributed to improved learning and feedback $(67.4 \%)$, and $77 \%$ were positive about the online assessment [10].

In a pre-exam survey, students indicated that they prefer typing rather than writing, feel more confident in the exam, and have limited software and hardware problems. With the same sample in the post-exam survey, as part of the design and technology exam, students felt that the software and hardware were easy to use, but many students did not feel comfortable after using the electronic exam. The results will be more informative if the social media discourse is analyzed using the network analysis, as described by Kolmakov et al. [11].

Some researchers have compared online examinations under the supervision and without him on several aspects, including the behavior when taking the test. Their study did not find any differences in students ' behavior when taking tests in the two environments. There was no significant difference between missing and missing elements. Also, as for a quick guess, there wasn't a significant difference. There was a slight difference for students over the age of thirty-five, but gender did not matte. 


\subsection{The occurrence of anxiety in students}

Scientists are increasingly aware of the role of test anxiety in reducing student performance in an online learning environment. The manuscripts identified by scanning the literature revealed inconsistencies in results regarding the effect of exam methods on students ' anxiety. A study by a group of psychology students found that students who typically experienced high anxiety in traditional testing settings had lower levels of anxiety when taking an online exam [12].

In a quasi-experimental study ( $\mathrm{n}=39$ nursing students), when basic anxiety was controlled, students on computer exams had a higher degree of test anxiety.

Among 38 graduate students surveyed, only three opposed online assessment based on a perceived lack of technical skills. About two-thirds of participants identified some form of fear based on disconnection from the Internet, electricity, slow typing, or family disturbances at home.

A study conducted at a college where 39 students were interviewed used proximal indicators (such as licking and biting the lips, frowning brows, and bending when sitting) to assess the level of test anxiety when checking exams using a webcam.

Teachers' strategies for reducing anxiety in their students include giving students the opportunity to review, analyze, and acknowledge their anxieties. Responses such as writing students' concerns or answering multiple-choice questionnaire about test anxiety reduce anxiety. Students in the test group who provided disturbing tasks or expressive written exercises showed better results [12].

\subsection{The use of fraudulent schemes in the exams}

Of all the topics identified, fraud was the most common area. Some argue that deception in asynchronous, objective, and online evaluations is at an unfair level. According to one survey, $73.6 \%$ of students found it easier to cheat on online exams than on regular ones. This may be due to the fact that students are monitored using paper and pencil exams, compared to online exams, where more control of variables is required to mitigate fraud [13].

Some instructors used randomized exam technology to minimize the possibility of cheating by sharing experiences between peers.

Scientists identify various methods of mitigating fraud. Detection test, prevention of theft on an exam, unauthorized use of textbooks, preparation of settings for online exams, unauthorized student access to the bank of tests, preventing the use of devices (e.g., phone, Bluetooth and calculators), restricting access to others during the exam, equitable access to hardware, identifying hardware or software failures, inconsistency of test methods. In another case, the problem of solving the problem of fraud is not only technical, but also social.

While modern technologies are considered to be the norm for reducing fraud, these tools are mostly ineffective. Access to multiple question banks through efficient quiz design and delivery is a mechanism for reducing the tendency to cheat by reducing bids through multiple delivery attempts [13].

Randomization of questions and answers, continuous question development, multiple exam options, open book options, timestamps, and a variety of question formats, sequences, types, and frequencies are used to control perception and the possibility of cheating. In a study with MBA students, the perception of the ability to cheat was found to be critical to creating a safe online exam environment. 
The authors select various fraud technologies used in online education of modern students:

- copying USB content to a hard disk to make a copy of the digital research available to others;

- using a virtual machine to maintain access to standard applications on your device;

- hacking a USB keyboard to make it easier to access other documents (such as personal notes);

- software modification to maintain full control over your own device;

- cold boot attack to save a copy of the study [14].

Research on deception has focused primarily on technical issues (such as hardware to support fraud), rather than ethical and social issues (such as behavioral development to deter fraud in the future). The latter has been explored more deeply in traditional assessment methods.

In a study on mass open online courses (MOOCs), students' motivation to participate in additional training was based on their knowledge, work, convenience, and personal interest. This provides possible opportunities for future research to consider behavioral elements for responding to deception, rather than institutional punishments.

\subsection{The perception of online technology and pedagogical personnel}

The authors also examined scientists ' perceptions of online exams. Scientists reported that their biggest problem when using online exams is the possibility of cheating. There was an opinion that students can be helped during the exam.

The reliability of technology is the second important issue for academic staff. This includes problems with your Internet connection, as well as problems with your computer or software. The third problem is related to ease of use for both academics and students. Scientists need a system that can easily and quickly create, manage, and evaluate exams, and students can use it with good ICT skills. In addition, in another study, employees reported that marking digital work was easier, and preferred it to paper exams. They believe that preference should be given to using University computers rather than students using their own computer, mainly due to problems with operating system compatibility and data loss [4].

\subsection{The issues of authentication and security}

Authentication was found to be a serious problem for verification. Some scholars point out that the main reason for requiring physical attendance at supervised exams is to verify and authenticate the student taking the exam. It is important to note that the validity of the procedures for conducting online examinations under the supervision lower than those conducted in person. Most responses to online exams use "bring your own device" models, where laptops are brought to traditional lecture halls, using software on personal devices in any desired location, or using prescribed devices in the classroom. The main goal of each of them is to balance student authentication and maintain the integrity and value of learning outcomes.

A review of current authentication options used fingerprint reading, media streaming, and subsequent identification to authenticate small groups of students. Some learning management systems (LMS) have developed additional products to support authentication processes [15].

Some biometric software uses different layers to authenticate keystrokes for motor control, stylometry for linguistics, application behavior for semantics, capture physical or behavioral patterns, extract unique data, compare distance measurements, and record 
decision making. The development of online exams should focus on the same theory of open book exams.

Some authors suggest using a number of on-site processes to develop exams that minimize fraud (for example, broad blocks of questions, improving authentication methods (for example, keystrokes and fingerprints), and conducting post-analysis of papers to search for fraud [15].

Another model proposed by the authors defines two perspectives for conceptualizing authentication systems: the examinee and the administrator. From the examinee's point of view, the authentication points before, during, and after the exam. From an administrative point of view, access to photographic authentication in the periods before and during the exam can be used to verify the examinee.

The "open book, open network" model uses the application of authentic assessment to put the student in the role of a decision maker and expert witness, with confirmation, avoiding any question that may have a general answer [16].

The smart authentication quick exam model uses app focus (for example, continuous tracking of the subject's focus), logging (phone status, phone identification, and Wi-Fi status), visual password (a password that is visually presented but difficult to transmit without a photo), Bluetooth neighbour logging (to check for nearby devices), ID verification, digitally signed app, random device swapping, and avoiding the use of "bring your own device" models [17].

The comprehensive online exam was used in the National Dental Exam Board to test knowledge at home with 200 multiple-choice questions and the ability to take the test multiple times to develop formative knowledge [18].

Some academics recommend online synchronous assessments as an alternative to traditional supervised exams, while retaining the ability to authenticate manually. In these assessments: quizzes are designed to test factual knowledge, practices for procedural, essays for conceptual, and oral for metacognitive knowledge. The "cyber-face-to-face" element is required for student verification.

\subsection{The perception of interface design}

Table 1. Evaluating the potential of interface design for online learning programs in high school.

\begin{tabular}{|c|c|c|}
\hline $\begin{array}{c}\text { Interface design } \\
\text { characteristics }\end{array}$ & Recommended value & Description \\
\hline Type font (size) & $10,12,14,18,22$ and 26 points & $\begin{array}{l}\text { Font size has a significant impact } \\
\text { on objective and subjective } \\
\text { readability and clarity. }\end{array}$ \\
\hline Type font (type) & $\begin{array}{l}\text { Andale Mono, Arial, Arial Black, Comic Sans } \\
\text { Ms, Courier New, Georgia, Impact, Times } \\
\text { New Roman, Trebuchet Ms, Verdana and } \\
\text { Tahoma }\end{array}$ & $\begin{array}{l}\text { Reading efficiency and reading } \\
\text { time are important aspects related } \\
\text { to font type and size }\end{array}$ \\
\hline Type font (style) & Regular, italic, bold, and bold italics & \\
\hline Colour Scheme & $\begin{array}{l}\text { Or: } \\
- \\
\text { Black text on a white background (standard) } \\
- \\
\text { Black text on a gray background (reduced) } \\
\text { - } \\
\text { White text on a black background (inverted) }\end{array}$ & $\begin{array}{l}\text { The colour of the text and } \\
\text { background affects the readability } \\
\text { of the text and colour, and a } \\
\text { higher contrast ratio usually leads } \\
\text { to better readability. }\end{array}$ \\
\hline
\end{tabular}




\begin{tabular}{|l|l|l|}
\hline Timer & $\begin{array}{l}\text { Countdown timer, rising counter and } \\
\text { traditional clock }\end{array}$ & $\begin{array}{l}\text { Online exam systems must } \\
\text { display a time counter on the } \\
\text { screen until the exam time runs } \\
\text { out. }\end{array}$ \\
\hline Information & $\begin{array}{l}5 \text { min }(\mathrm{M}) \text { left, 15 million left, 30 million left, } \\
\text { mid-exam and no warning }\end{array}$ & $\begin{array}{l}\text { You can use a warning to inform } \\
\text { you about the remaining research } \\
\text { time. }\end{array}$ \\
\hline
\end{tabular}

The interface of the system will influence whether the student perceives the environment as a means or obstacle to online exams. In the literature, generalization of the potential features of the interface design in the context of this topic. The inclusion of navigation tools was also identified by students and staff as an important design feature, as was the auto-save feature [19].

\subsection{Technological problems}

In this section, only some students reported a conflict between the system and the computer software, and also complained about the slow speed of the system. Technical problems that made it impossible to complete the exam were not reported in the literature.

In a separate study, students reported that they would prefer to use university technology to complete the exam because of distrust of the system that works with their home computer or laptop operating system, or for fear of losing data during the exam. Although the study did not report any problems with desktop loading, some student laptops in the workplace had firewalls, and so they had to load the system from USB [20].

Thus, it can be determined that for the majority of students, the online learning environment has created a system that is more favorable for their well-being, personal life and academic performance. Staff preferred online exams because of their workload and ease of completion, and a basic print-based assessment of exam logistics could reveal significant ongoing cost savings. Not all staff and students preferred the idea of online testing, but studies that took age and gender into account found only minor differences.

Although the literature on online exams is growing, there is still little discussion at the pedagogical and managerial levels. As a result of the analysis, it was possible to identify two relevant areas of research-accreditation and authenticity. There are also many possible ways to consider the consistency of applications, the validity and reliability of online exams, and whether online exams can better evaluate and improve student performance. There are also opportunities to synthesize online exam literature with other innovative digital teaching devices. For example, an immersive learning environment, mobile technologies; social media and Web 2.0 technologies [21].

A number of key issues related to online exams also need to be addressed. These include the need for online exams to be accessible, the need to be able to distinguish true passing from true failure, security, minimizing the possibility of cheating, accurate student authentication, reducing assessment time, and software flexibility or technological failure.

At the heart of university decisions to use face-to-face and supervised exams is the provision of learning authentication, a requirement of many governing bodies around the world. Constantly updating the rules allows you to be sure that students are exactly who they say they are.

However, sophisticated networks have been created all over the world to support direct cheating of students from performing quick assessments and calculators with the ability of a secret search engine to complete the course, including attending controlled exams on the University grounds. The authentication process for controlled exams usually does not take into account part-time students who have fake student ID cards that allow them to pass the exams for another student. According to the requirement to guarantee the authenticity of training, online exams must meet modern conditions. The inclusion of a wider range of big 
data from keystroke patterns, linguistic analysis, and student-wide analysis over the course of a student's life cycle is necessary to identify areas of risk from an institutional perspective [22].

A pilot study on fraud detection in the psychological Department showed that teachers can detect fraud in $65 \%$ of cases. Automated algorithms can be used to support preidentification of this process, given that lecturers and professors are unlikely to assume that several hundred student papers on the same topic show signs of fraud. It is in the written works of students that individuality should be manifested [10].

The evolution of pedagogy and teaching principles has led to a revision of approaches to student assessment and learning. However, universities are slower to innovate, despite growing evidence that students prefer the flexibility and opportunities provided by digitalization of exams. The University commitment to developing an authentic assessment environment will require a radical revision of current exam practice to include real learning processes and unstructured problem solving.

While traditional exams may depend on financial performance, accreditation, and authentication, there is increasing pressure from student demand, academic performance, and student well-being to create more authentic learning opportunities.

Setting up an online exam offers a great opportunity to connect to those environments that graduates will need to participate in on a regular basis. The development of time management skills to plan time for taking the exam at a fixed time is reflected in the student's need to make a presentation and speak at certain times of the day to corporate stakeholders [23].

Completing a self-regulating online task with tangible results is reflected in many roles, from time-sensitive legal briefs to high school teachers filling out student reports at the end of the calendar year. Implementation and evaluation of the future practitioner should focus on ensuring authenticity in the exam setting. future researchers should strive to better understand the parameters by which online exams can create an authentic learning experience for students. In some cases, it may not be appropriate to include exams; in these cases, they should be gradually excluded from the curriculum.

As educational institutions begin to provide students with greater learning flexibility through digital and mixed offerings, there is a scientific need to consider the effectiveness of the examination environment associated with these conditions. Home computers and high-speed Internet are becoming commonplace, recognizing that this assumption has implications for student equality [24].

In the future, research on students' fluency in digital technologies will be crucial. Also important is the scientific imperative to examine the barriers to implementation and success associated with online exams in higher education, given the lack of clear interagency case studies.

There is also a symbiotic issue that needs to be addressed by scientists in our field, starting with understanding how online exams can contribute to higher education, as well as how higher education can influence the conduct online exams.

\section{Conclusions}

The paper examines modern publications in the organization of online exams. The main attention in literature is paid to preliminary estimates of implementation. These include the following: what processes have changed at the technological level, and how students and staff evaluated their preferences. Initially, attempts were made to study the impact of online exams on students' well-being and academic performance, as well as how these changes affect employees' ability to achieve results. 
Higher education institutes need to understand the obstacles and ways to overcome them that contribute to the wider spread of online exams in higher education, since it is necessary to improve adaptation capabilities of all the learning process participants [25]. One of the biggest obstacles is the perception of using online exams. After students have passed the online exams, preference is given to this format because of its ease of use.

The authors believe that student performance did not significantly differ in final exam scores for online exams and traditional exams. Students' anxiety decreased when they used software for online exams. This information should be provided to students in order to change the perception of students and reduce anxiety when implementing an online exam system.

When choosing a training system, universities should look for one that includes biometric data with a high level of accuracy, such as user authentication, as well as monitoring movement, sound, and keystrokes (a message about deviations so that you can view the recording). These features reduce the need for online exams. Other system features should include system or browser blocking, cloud technologies to avoid requiring local updates, and an interface design that makes using the online exam intuitively understandable. Universities should also think about how they will address technological errors and digital inequality.

In the future, it is necessary to study the current use of online exams in disciplines, institutions and countries to understand the successes and disadvantages. In addition to questions about "whether students prefer online exams or on-site exams", serious questions about how to improve mental well-being, employment opportunities, and achievement of learning outcomes from online exams are critical.

\section{References}

1. H. AbuMansour, Proposed bio-authentication system for question bank in learning management systems IEEE/ACS 14th international conference on computer systems and applications (AICCSA) (2017)

2. M. Reza, D.T.H. Manurung, V.V. Kolmakov, A.S. Alshebami, Impact of education and training on performance of women entrepreneurs in Indonesia: Moderating effect of personal characteristics, Management Science Letters 10 (16), 3923-3930 (2020)

3. A.V. Glotko, A.G. Polyakova, M.Y. Kuznetsova, K.E. Kovalenko, R.A. Shichiyakh, M.V. Melnik, Main trends of government regulation of sectoral digitalization, Entrepreneurship and Sustainability Issues 7 (3), 2181-2195 (2020)

4. K. Chebrolu, B. Raman, V.C. Dommeti, A.V. Boddu, K. Zacharia, A. Babu, P. Chanda n, Safe: Smart authenticated Fast exams for student evaluation in classrooms, Proceedings of the 2017 ACM SIGCSE technical symposium on computer science education 117-122 (2017)

5. V.V. Kolmakov, L.N. Rudneva, Y.E. Thalassinos, Public survey instruments for business administration using social network analysis and big data, International Journal of Economics and Business Administration 8 (2), 3-18 (2020)

6. M. Alzu'bi, The effect of using electronic exams on students' achievement and test takers' motivation in an English 101 course, Proceedings of conference of the international journal of arts \& sciences 207-215 (2015)

7. A. Amigud, P. Dawson, The law and the outlaw: is legal prohibition a viable solution to the contract cheating problem? Assessment \& Evaluation in Higher Education 45 (1), 98-108 (2020) 
8. M. Ardid, J.A. Gómez-Tejedor, J.M. Meseguer-Dueñas, J. Riera, A. Vidaurre, Online exams for blended assessment. Study of different application methodologies, Computers \& Education 81, 296-303 (2015)

9. A. Fluck, O.S. Adebayo, S.I.M. Abdulhamid, Secure e-examination systems compared: Case studies from two countries, Journal of Information Technology Education: Innovations in Practice 16, 107-125 (2017)

10. P. Dawson, W. Sutherland-Smith, Can training improve marker accuracy at detecting contract cheating? A multi-disciplinary pre-post study, Assessment \& Evaluation in Higher Education 44 (5), 715-725 (2019)

11. I.G. Kuznetsova, A.G. Polyakova, L.I. Petrova, E.I. Artemova, T.V. Andreeva, The impact of human capital on engineering innovations, International Journal of Emerging Trends in Engineering Research 8 (2), 333-338 (2020)

12. Q.N. Hong, S. Fàbregues, G. Bartlett, F. Boardman, M. Cargo, P. Dagenais, M.P. Gagn on, F. Griffiths, B. Nicolau, A. O'Cathain, M.C. Rousseau, I. Vedel, P. Pluye, The mixed methods appraisal tool (MMAT) version 2018 for information professionals and researchers, Education for Information, 34 (4), 285-291 (2018)

13. A. Margaryan, A. Littlejohn, G. Vojt, Are digital natives a myth or reality? University students' use of digital technologies, Computers \& Education 56 (2), 429-440 (2011)

14. K. Butler-Henderson, J. Crawford, J. Rudolph, K. Lalani, K.M. Sabu, COVID-19 in Higher Education Literature Database (CHELD V1): An open access systematic literature review database with coding rules, Journal of Applied Learning and Teaching 3 (2) (2020)

15. A. Karp, Exams in algebra in Russia: Toward a history of high stakes testing, International Journal for the History of Mathematics Education 2 (1), 39-57 (2007)

16. H. Nguyen, A. Henderson, Can the reading load be engaging? Connecting the instrumental, critical and aesthetic in academic reading for student learning, Journal of University Teaching and Learning Practice 17 (2), 6 (2020)

17. C. Böhmer, N. Feldmann, M. Ibsen, E-exams in engineering education-online testing of engineering competencies: Experiences and lessons learned IEEE global engineering education conference (EDUCON) 571-576 (2018)

18. L. Daffin Jr., A. Jones, Comparing student performance on proctored and nonproctored exams in online psychology courses, Online Learning 22 (1), 131-145 (2018)

19. K.J. Chao, I.C. Hung, N.S. Chen, On the design of online synchronous assessments in a synchronous cyber classroom, Journal of Computer Assisted Learning 28 (4), 379395 (2012)

20. S. Ellis, J. Barber, Expanding and personalizing feedback in online assessment: A case study in a school of pharmacy, Practitioner Research in Higher Education 10 (1), 121 129 (2016)

21. K. Hylton, Y. Levy, L.P. Dringus, Utilizing webcam-based proctoring to deter misconduct in online exams, Computers \& Education 92, 53-63 (2016)

22. Q. Chen, An application of online exam in discrete mathematics course, Proceedings of ACM turing celebration conference-China 91-95 (2018)

23. A. Steel, L.B. Moses, J. Laurens, C. Brady, Use of e-exams in high stakes law school examinations: Student and staff reactions, Legal Education Review 29 (1), 1 (2019)

24. J. Pagram, M. Cooper, H. Jin, A. Campbell, Tales from the exam room: Trialing an eexam system for computer education and design and technology students, Education Sciences 8 (4), 188 (2018) 
25. V.O. Gerasimov, R.I. Sharafutdinov, V.V. Kolmakov, E.A. Erzinkyan, A.A. Adamenko, A.G. Vasilyeva, Control in the human capital management system in the strategy of innovative development of a region, Entrepreneurship and Sustainability 7 (2), 1074-1088 (2019) 